\title{
Seven Decades of Levothyroxine: A Comprehensive Profile
}

Leonidas H. Duntas

Received: August 21, 2019 / Published online: September 4, 2019

(C) The Author(s) 2019

"...the past is useful if it points to the present and the present is beneficial if it looks forward to the future." *

* Zirogiannis PN. A Medical Vade Mecum.

Motivating insights to new doctors. Ed. Athens Medical Association, pp 194-195, 2017

The prevalence of hypothyroidism varies depending on geography (e.g., it is somewhat higher in Europe than in the USA), populations studied, and definition [1]. Age is also a crucial factor, since, worldwide, its prevalence is greater among the elderly, standing, for example, at about $7 \%$ in individuals aged between 85 and 89 years [2]. Among all age groups, however, the actual percentages are most likely to be substantially higher, given that no age-specific reference range for TSH is currently applied, while the disease often remains undiagnosed.

The main causes are iodine deficiency (ID) and autoimmune thyroiditis. In iodine-sufficient regions, the prevalence of hypothyroidism ranges from 1 to $2 \%$, while these figures rise to $5 \%$ in areas with ID [1]. Taking into account the fact that ID affects about one-third of the global population and that in children it has devastating effects on neurologic development and

L. H. Duntas $(\bowtie)$

Evgenideion Hospital, Unit of Endocrinology, Diabetes and Metabolism, University of Athens, 10528 Athens, Greece

e-mail: ledunt@otenet.gr cognition, hypothyroidism constitutes a public health concern at all stages of life. Timely and optimal diagnosis and treatment are thus essential.

It was in June 1890 in Lisbon that Bettencourt and Serrano, drawing on animal work as well as on earlier important confirmation that myxoedema and cretinism were due to absence or degeneration of the thyroid, carried out the first experimental grafting of a sheep's thyroid. Specifically, they inserted half of a sheep's thyroid subcutaneously into the inframammary region of a woman suffering from myxoedema and cretinism [3]. The graft was successful, while the scientists' revolutionary hypothesis based on this intervention was that the success was simply due to absorption of fluid from the grafted gland.

On 13 April 1891, George Murray injected a 46-year-old female, presenting characteristic features of myxoedema, with $1.5 \mathrm{ml}$ of thyroid extract [4]. Based on his success-the patient survived nearly 30 years-he proposed the use of hypodermic injections of thyroid extracts for treatment of myxoedema.

Although isolated in 1914, levothyroxine (LT4) was not commercially synthesized until 1949 and entered the market during the following 2 decades. Since then, LT4 has become one of the most prescribed drugs in the world, and, according to the American Thyroid Association and European Thyroid Association Guidelines [5, 6], LT4 monotherapy is today 
recommended as first-line treatment for all forms of hypothyroidism.

The fact that LT4 has a narrow therapeutic index resulted in the FDA's endorsing an approved requirement of $95-105 \%$ potency specification for all LT4 compounds throughout their shelf life $[7,8]$. This requirement, in addition to the FDA's earlier declaration of LT4 products as "new drugs" due to reported inconsistencies regarding the potency and stability of some compounds, led to changes in the production policy of many manufacturers. The consequence has been the production of LT4 tablets of high quality with regard to both precision and efficacy.

To commemorate the landmark discovery of thyroxine that has given new hope to millions of people suffering from thyroid insufficiency, this special issue of Advances in Therapy is hosting three outstanding articles dedicated to LT4 for the treatment of hypothyroidism, a disease with considerable impact on the health and quality of life of patients around the world. The articles also enumerate and discuss specific factors that may aggravate hypothyroidism, such as severity of disease, comorbidities, and age, and that can reduce the effectiveness of treatment modalities.

The first article by Flavia Magri and Luca Chiovato points to the fact that LT4, one of the most prescribed medications in the world, is on the WHO's Model List of Essential Medicines. They discuss its major role in treating hypothyroidism as well as both its benefits and its downsides in the treatment of subclinical hypothyroidism.

The second article, written by Leonidas Duntas and Jacqueline Jonklaas, explains the importance of LT4 dose optimization in patients with hypothyroidism. In these individuals, initially the dose can vary greatly, while, additionally, adjustments can also occur throughout the patient's lifespan in accordance with their changing clinical needs and conditions. Examples of the latter are during pregnancy, after significant weight gain or loss, following surgery, and in the presence of comorbidities, when additional medications are needed.
The third article by Alan Carlé and Salvatore Benvenga deals with the wide range of generic and branded levothyroxine formulations available, as well as the pharmacologic differences (excipient, content, pharmacokinetics) among the various compounds. The authors also discuss the effects of formulation interchange on dose decision, efficacy, outcome, and adverse events.

The articles, apart from being up to date and highly informative, are, in effect, a tribute to LT4, an eminently safe and reliable drug and a "faithful" mainstay of physicians worldwide in their efforts to reverse the adverse effects of the various forms and degrees of hypothyroidism. The upcoming introduction of new formulations and re-formulations of the present LT4 compounds in order to meet the strict criteria of potency specification are lights on the path to an even brighter future of ever greater quality and efficacy.

\section{ACKNOWLEDGEMENTS}

Funding. The Rapid Service Fee, Open Access fee, printing, and distribution of these three articles in the Levothyroxine collection were made possible thanks to an educational grant received from Merck KGaA, Darmstadt, Germany.

Authorship. All named authors meet the International Committee of Medical Journal Editors (ICMJE) criteria for authorship for this article, take responsibility for the integrity of the work as a whole, and have given their approval for this version to be published.

Disclosures. Leonidas H. Duntas has no conflict of interest to disclose.

Compliance with Ethics Guidelines. This article is based on previously conducted studies and does not contain any studies with human participants or animals performed by any of the authors. 
Open Access. This article is distributed under the terms of the Creative Commons Attribution-NonCommercial 4.0 International License (http://creativecommons.org/licenses/ by-nc/4.0/), which permits any noncommercial use, distribution, and reproduction in any medium, provided you give appropriate credit to the original author(s) and the source, provide a link to the Creative Commons license, and indicate if changes were made.

\section{REFERENCES}

1. Taylor PN, Albrecht D, Scholz A, Gutierrez-Buey G, Lazarus JH, Dayan CM, Okosieme OE. Global epidemiology of hyperthyroidism and hypothyroidism. Nat Rev Endocrinol. 2018;14(5):301-16. https://doi. org/10.1038/nrendo.2018.18.

2. Gussekloo J, van Exel E, de Craen AJ, Meinders AE, Frölich M, Westendorp RG. Thyroid status, disability and cognitive function, and survival in old age. JAMA. 2004;292(21):2591-9.
3. Bettencourt R, Serrano JA. Un cas de myxoedème traité par la greffe hypodermique du corps thyroïde d'un mouton. La Semaine Médicale. 1890;10:294.

4. Murray GR. Myxoedema. In: Northumberland and Durham Med Soc minute book. University of Newcastle, Archives. 1891;12:91-93.

5. Pearce SH, Brabant G, Duntas LH, Monzani F, Peeters RP, Razvi S, Wemeau JL. 2013 ETA guideline: management of subclinical hypothyroidism. Eur Thyroid J. 2013;2(4):215-28. https://doi.org/10.1159/000356507.

6. Jonklaas J, Bianco AC, Bauer AJ, Burman KD, Cappola AR, Celi FS, Cooper DS, Kim BW, Peeters RP, Rosenthal MS, Sawka AM, American Thyroid Association Task Force on Thyroid Hormone Replacement. Guidelines for the treatment of hypothyroidism: prepared by the American thyroid association task force on thyroid hormone replacement. Thyroid. 2014;24(12):1670-751. https:// doi.org/10.1089/thy.2014.0028.

7. http://www.fda.gov/cder/drug/infopage/levothyrox ine/qa. Accessed 19 Sept 2016.

8. Hennessey JV. The emergence of levothyroxine as a treatment for hypothyroidism. Endocrine. 2017;55(1): 6-18. https://doi.org/10.1007/s12020-016-1199-8. 